\title{
SUSTAINABILITY OF INTEGRATED FINANCIAL REGULATION AND SUPERVISION IN THE EUROPEAN UNION
}

\section{Sulejman AHMEDI}

Faculty of Law, University of Tetovo, Str. Ilinden bb, Tetovo, Republic of N. Macedonia Correspondence: sulejman.ahmedi@unite.edu.mk sulejman.ahmedi@aso.mk

\begin{abstract}
Financial regulation and supervision are some of the most important components of the financial stability of any economy. The applied institutional framework, i.e., the model and structure of the organization of financial regulation and supervision is crucial for the overall stability as well. The first question to be addressed when choosing a model or the combinations of different structures encompasses to the decision that needs to be made regarding the integrated or the non-integrated system of financial supervision. The traditional sectoral approach for financial supervision is not that effective enough to respond to the growing trend of financial conglomeration. Consequently, the integrated regulation is increasingly present in many countries around the world. During the last two decades, the development of financial regulation is moving in the direction of institutional consolidation. The purpose of this paper is to point out the issue of choosing a model of regulation and supervision in the EU countries in the context of the development of financial conglomerates and complex integrated financial products. The research hypothesis argues that the applied model of integration of financial supervision in the EU member states meets the needs of their financial systems, which are increasingly determined by the complexity of the financial conglomerate.
\end{abstract}

KEYWORDS: financial system, financial supervision, integrated and non-integrated, European Union

JEL CLASSIFICATION: G18; G28; K20; L50 
INTRODUCTION

The financial system is one of the most complex regulated sectors in any national economy. Regulation and supervision of the financial system include defining rules and setting up control mechanisms for the operation of the financial institutions and markets. Definition and implementation of the regulatory framework ensures stability and liquidity of the financial system, while promoting competitiveness and market efficiency.

The existence of a system of regulation and supervision is particularly relevant to investors, because it provides access to high quality information, i.e., alleviates the problems of negative selection and moral hazard.

Goodhart (2000) lists three key goals that the regulation seeks to achieve, as follows:

- Ensuring systemic stability of the financial system, i.e., preventing financial panic that could collapse the entire economy,

- Insurance against monopoly behavior in the financial service providers,

- Investor protection, with emphasis on the most vulnerable target group of small investors.

Regulators, supervisors, policymakers, and the general public have questioned the effectiveness of financial supervision, both in the state of turmoil and financial market crises in recent years (Cukierman, 2011). The question whether modifications in the existing supervision models are needed is also a permanent topic of discussion. History has shown that financial market crises have often been accompanied by regulatory reforms. They both unite under the common goal: to regulate and supervise financial markets and institutions in an optimal manner.

In the last twenty years, financial regulation has been developed rapidly in the light of globalization processes and the growth of financial conglomerates. Financial conglomerates are the most common institutional form of ownership and market links. The above-mentioned types of organizational forms represent the evolutionary result of modern financial markets and show the direction of future changes in financial systems. A financial conglomerate is broadly defined as "A group of jointly controlled companies whose exclusive or dominant activities consist of providing most of the services in at least two different financial sectors: insurance, banking or capital markets (BIS, 2012). The conglomerate is usually dominated by a bank or an insurance 
company and is followed by owner-subordinated institutional investors such as: mandatory and voluntary pension funds, leasing companies, open-end or closed-end investment funds. The conglomeration of the financial system has reached the top of scale in the system of European universal banking and insurance, primarily due to the lighter regulation of the cross-sectoral activities of the financial intermediaries.

As of 2018, the dominant model for financial supervision is the integrated model. It is represented in seventeen member states of the EU (Austria, Belgium, the United Kingdom, Germany, Denmark, Estonia, Ireland, Latvia, Lithuania, Malta, Poland, Slovakia, Finland, Hungary, Finland, the Czech Republic, and Sweden), either within the framework of the central bank or through a unified regulator outside the central bank. At the same time, for the first time since 2000, some member states, which have previously had a unified regulator outside the central bank, have changed the oversight model by adopting the "twin peaks" model (Belgium and the United Kingdom), and in both cases, the prudential oversight has been assigned under the jurisdiction of the central bank (Schoenmaker and Veron, 2017). The "twin peaks" model is represented in five member states (Belgium, the United Kingdom, Italy, France and the Netherlands) with these modifications. Five other countries (Bulgaria, Greece, Luxembourg, Romania, and Croatia), that have retained elements of the sectoral model, have introduced a partial integration of the oversight over some financial sectors. In Bulgaria, Croatia, and Romania, the non-banking supervisors are partially integrated outside the central bank, while the banking supervision is retained in the central bank; Greece has pursued an integration of the banking and the insurance supervision within the central bank; and Luxembourg has a single supervisory body responsible for overseeing banks and securities and a separate body for overseeing insurance companies, both located outside the central bank. With the last structural reforms, the sectoral model in its basic form remains present only in three countries (Cyprus, Slovenia, and Spain) and, with some variations, in Portugal (Nakeva Ruzin, and Jovanovski 2020).

Therefore, it seems justified to examine the reasons that led to these dynamic changes in the institutional order of the supervision system in the EU countries. The focus of this paper will be on the development of infrastructure models of supervision as well as aspects of possible solutions. 
The research will make it clear how integrated financial regulation and supervision, i.e., their application can be more effective for monitoring the risks of the entire financial system by responding to possible threats to the stability of financial systems.

\section{MODELS OF GOVERMENT REGULATION AND SUPERVISION IN THE FINANCIAL SECTOR}

Regulation is adopted as an alternative to anti-trust policy in the case where the competition is considered unfeasible or in the case where the activity must be controlled due to monopolistic tendencies. For example, natural monopolies have licenses, and their pricing decisions are controlled in order to protect the consumers from exploitation. Cartelized activities are regulated for the same reasons. Here, regulation is needed due to lack of competition, and it is required to achieve results similar to those that would exist in the competitive activity.

In financial sectors, the problem of monopoly is not so significant, yet there are several reasons for government control. Namely, it is indisputable that there is competition in the financial sector and almost negligible possibility for the existence of monopolies. Furthermore, the self-regulation in the market imperfection conditions can lead to numerous negative implications and disturbances, primarily due to the adverse selection and ex-post action. The need for regulation in the financial sector differs from that in monopolized or cartelized sectors, because potential market failures are different as well. The first of the potential market failures stems from the credible nature of financial operations, and the second one from the uncertainties inherent in the price formation process.

The regulation of modern financial systems is developing in three basic directions, as follows (Olgić, 2012):

1. Corporate governance - regulation and supervision are performed only by the company itself;

2. Self-regulation - regulation and supervision of the financial markets and the institutions, implemented by the individual financial institutions or from the industry associations; 
3. Direct government regulation - regulation and supervision of the financial system defined by the legislative framework implemented by the public oversight body.

Over the last twenty years, regulation has developed rapidly in the light of the processes of globalization, deregulation of financial markets and the strengthening of conglomeration in almost all economies. In addition, the trend towards global financial integration corresponds to the emergence of financial crises (Olgić, 2012). Van der Zwet (2003) lists various infrastructure supervision solutions according to the degree of growing integration, as follows:

1. Strengthening the link between sectoral financial supervisors (solo or sectoral supervision) - most often related to the separation of institutions responsible for banking, insurance and capital market supervision;

2. Twin peaks model - a model that includes the establishment of a supervising agency for all types of financial institutions, as well as institutions responsible for "strengthening an orderly and transparent financial market and proper relations between market participants". For example, the Central Bank is directly responsible for the systemic stability of the financial system and has the role of the so-called lender as a last resort (prudent regulation). On the other hand, market conduct supervision (Conduct of business; product regulation) refers to strengthening measures to protect investors, preserve market integrity and improve competitiveness, as well as measures to improve the quality of information for market participants. Rather than a monopoly on a regulatory body, this model creates a kind of regulatory duopoly. This model permits the mitigation of conflicts of interest between promoting the solvency of financial institutions and ensuring sufficient protection for their clients and investors (Schoenmaker and Véron, 2017).

3. Establishment of a single regulatory agency that includes banking, insurance and financial market supervision, independent of the central bank.

4. Establishment of a single regulatory agency for the entire financial system out of hand of the national central banks. 
FACTORS THAT INFLUENCE THE CREATION OF A SUSTAINABLE SUPERVISION STRUCTURE

a) Internationalization and integration of the EU financial markets

The integration of European financial systems through the merging of financial markets and cross-border services offered by the financial institutions is of paramount importance for the overall project of the European integration. The common market in financial services is extremely important for the functioning of the European internal market for goods, services and labor. At the same time, the integration of the financial system is essential for the functioning of the monetary union, and above all, for the operations of the European Central Bank (hereinafter referred to as the ECB) as the sole central bank of the Eurozone member states.

Successful transmission of the ECB monetary policy is impossible in conditions of fragmented financial markets. Therefore, one of the priorities in the creating of the monetary union has been the creation of conditions for full integration of the financial markets. However, this integration precisely, which has remained incomplete has been portrayed, at least in Europe, as one of the main amplifiers of the financial crisis and as a root cause for passivity and insufficient readiness to solve problems in the financial system. The unfinished integration of the financial markets, in the conditions of the financial crisis, pointed out the financial sector as the Achilles heel of the European Monetary Union 1 .

\section{b) Convergence of market segments}

In today's age of globalization and internationalization, the boundaries between financial segments are becoming increasingly blurred. If so, then the principle "Same business, same risk, same rules" should be implemented. All institutions should operate with the same rules. It should also be noted that the need for integration of supervisors in different sectors depends on the emergence of financial conglomerates as in "allfinanz" and "bank assurance". There is no doubt that if the market is dominated by that type of institution, then the issue is particularly related to it. Today, of course, the reality is different, and consequently, the entire EU financial supervision structure does not meet the above requirements. It contains the following weaknesses:

\footnotetext{
${ }^{1}$ http://www.ecb.europa.eu/press/key/date/2014/html/sp140212.en.html
} 
- Regarding the effectiveness of financial supervision: a fragmented structure of financial supervision increases the risk of termination in one market, will have consequences and will affect other markets. At the same time, a fragmented supervisory structure will transfer the risk that the information to be assessed as a risky situation of a financial group, and consequently, will not be shared equally among the supervisors involved in the situation.

- Regarding the effectiveness of financial supervision: The fragmented structure of financial supervision creates dual reporting tasks and creates unstable requirements for international financially active institutions.

The issue of international competition: the inefficiency of the existing supervisory regime weakens the competition of the EU financial services in the global competition.

\section{SELECTION OF A SUSTAINABLE MODEL OF INTEGRATED SUPERVISION}

The 2008 financial crisis brought to disclosed all the imperfections of the European financial system and the problems regarding its functionality. The incomplete integration of the financial services market prevented a quick solution and an appropriate response to the crisis; moreover, put in question the normal functioning of the monetary union, and thus, endangered the credibility of the euro as a common currency.

However, the financial crisis was also a kind of "momentum" for completing financial integration through the creation of the European system of financial supervision, which will contribute to a greater stability of the overall European financial system, better transmission of monetary policy within the Eurozone, as well as strengthening the euro as a direct competitor to the dollar as the world reserve currency.

The suggested reform measures would consolidate the European financial stability framework into a hybrid twin peaks model illustrated on Figure 1. Apart from the slight discrepancy between the envisaged centralized supervisory, resolution, and central banking arrangements on one side, and the at least initially nationally organized and sectoral separated safety net on the other side, the new system would be coherent and a great deal simpler than the current architecture. Due to its integrated nature, clear division of responsibilities, and efficient coordination 
mechanisms, the new framework would better reflect today's interconnected financial landscape and more easily cope with the thereby posed challenges (Erdélyi, 2015).

Figure 1. Hybrid twin peaks EU financial stability framework

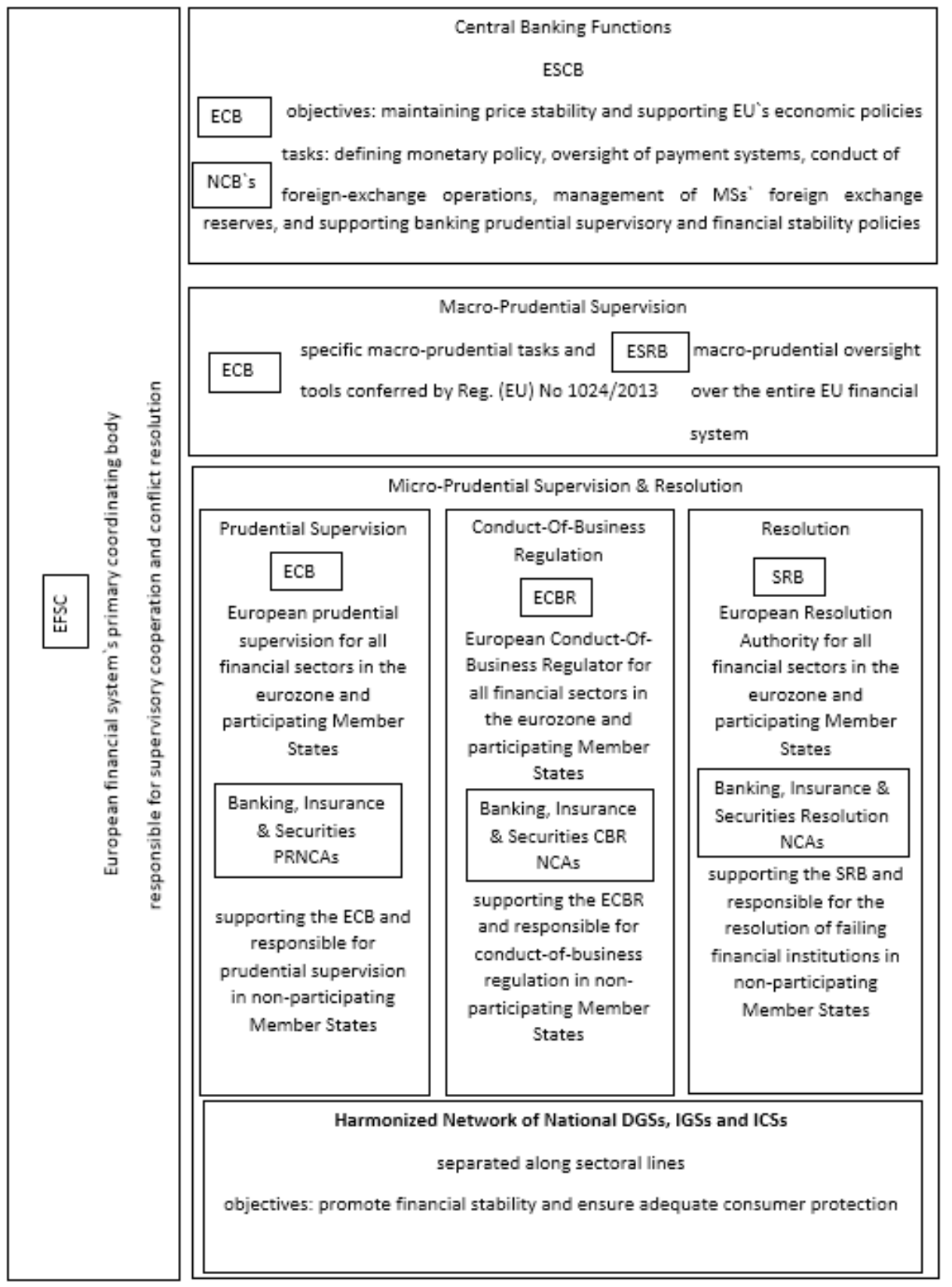

Source: Erdelyi, O J. (2015) Twin Peaks for Europe: State-of the-Art Financial Supervisory Consolidation, Springer

The foregoing analysis shows that there are a number of complexes, interrelated issues to consider when devising financial stability architectures or contemplating regulatory and supervisory reforms. Any such reform must be 
performed with caution under due consideration of a particular jurisdiction's specific circumstances, and mindful of any possible negative externalities together with the fact that regulators and regulated entities alike need time to adapt to changes. Slow progress through incremental reforms that are carefully aligned with existing regulatory structures and traditions are often a superior alternative to a radical transformation of the financial supervisory system (Erdélyi, 2015).

Despite the great diversity of financial stability frameworks employed around the globe, there are a few features generally thought to be integral to their success. As these characteristics can serve as useful starting points for further deliberations irrespective of the specific design of such systems, it seems appropriate to conclude this section by a short review of them (NIER, 2009):

- Ability to Adapt and Evolve: Policymakers and regulators involved in financial supervision unequivocally stress the significance of financial stability frameworks' ability to adapt to financial innovation and evolve with the rapidly changing financial environment.

- Human Capital and Regulatory Culture: Effective financial supervision depends much more on regulatory culture and the quality of human capital than on specific supervisory structures. Strong leadership and high-quality staff can at least temporarily make suboptimal financial frameworks work effectively until the necessary reforms are carried out.

- Appropriate Assignment of Regulatory Objectives: It is of crucial importance that the two objectives of financial regulation are identified-systemic risk reduction and consumer/investor protection-are assigned to one or more regulatory agencies in a manner that each agency making part of the regulatory landscape has a consistent set of objectives creating regulatory synergies and avoiding inter-agency conflicts. Conflicting objectives are thereby best allocated to separate institutions.

- Appropriate Allocation of Regulatory Tools: In order to ensure clear accountability and maximum efficiency of regulators, they must be equipped with powers corresponding to their responsibilities-that is, with the tools necessary to achieve their regulatory objectives. The allocation of regulatory tools should ideally take account of potential synergies and conflicts between particular tools as well.

- Separation of Micro- and Macro-Prudential Supervision: In response to the current financial crisis, there has been an increased trend of functional and 
institutional distinction between micro-and macro-prudential supervision. This separation of powers is believed to introduce vital supervisory checks and balances with a potential to better align supervisory incentives by improving supervisory governance and, thereby reducing the probability of regulatory capture.

- Increased Central Bank Involvement: Crisis experience makes a strong case for extending central banks' financial stability mandates. There is an incipient consensus that these institutions should play a major role in both macro prudential supervision and the supervision of systemically important financial institutions, and be formally involved in crisis management.

- Coordination, Cooperation\& Conflict Resolution: With hindsight to the most recent economic and financial crisis, it is also conventional wisdom that no financial regulatory architecture-however sophisticated it is-can function without effective coordination and cooperation arrangements between all regulatory agencies (including central banks and finance ministries) involved. This applies both within the borders of a single jurisdiction and worldwide, and preferably at all-principal and lower operational-levels of those regulatory agencies. Moreover, formal conflict resolution mechanisms are pivotal in mitigating the impact of potential inter-agency conflicts.

- Regulatory Consolidation: The last few decades are characterized by a trend of regulatory unification towards the integrated and twin peaks approaches. Lowering the number of regulatory agencies has proven to be helpful in reducing inter-agency frictions, the risk of duplication of supervisory tasks, and the regulatory burden on the industry.

- Consistency with Existing Settings: Any reform of regulatory architectureswhether allocating new powers and responsibilities to existing agencies or performing structural changes-must be consistent with the existing functional and structural settings of the supervisory framework concerned.

- Financial Safety Nets (Schich and Kim 2011): Financial system guaranteesin particular DGSs and in the recent past increasingly insurance guarantee and investor compensation schemes as well-are widely seen as indispensable elements of any financial regulatory system contributing to both objectives of financial regulation, e.g., mitigating systemic risk and ensuring sufficient consumer protection. 
However, there are also several perceived disadvantages of the twin peaks model. First, twin peaks may create a regulatory overlap with dual-regulated entities. The twin peaks model means that it is 'inevitable that two separate regulators would have two separate rule books and two separate systems' (Godwin, 2017) .

Of course, the proposed financial supervisory architectural design is merely one of several possible alternatives, but it seems a reasonably viable one in light of the ongoing trend toward financial supervisory consolidation and the above outlined considerable benefits associated with it.

\section{CONCLUSION}

A well-developed and efficient financial system is a key component at every national level in the economy. The impact of the financial system on economic growth and development is very important, but it also has a significant risk of shocks and instability. Therefore, it is especially important to set up control mechanisms and to implement an efficient and reliable system of supervision and oversight.

The evolution of the supervisory system in the last two decades can be characterized as particularly dynamic and intense. On one hand, financial systems developed faster than national economies in the mid-1990s, sophisticated products and services were introduced, and financial institutions were no longer unambiguously defined. The trend of consolidation of different financial sectors has been set and the question of the justification of the prevailing model of sectoral approach to financial supervision and supervision at the national level has been raised.

Finally, the global financial crisis has highlighted more than just the need for national integration of the supervisory system into a single institution, but also the need for new institutions at the supranational level. This issue is especially important in the conditions of high degree of integration of the financial market in the EU countries, and especially in the new member states that are characterized by underdeveloped financial systems, sensitive to external influences.

At the EU supranational level, there is a consensus among Member States on the need to strengthen the existing institutional structures for financial stability in order to ensure greater efficiency and cooperation between institutions for supervision. Accordingly, the financial crisis has encouraged the implementation of a new supranational framework for financial market supervision and institutions operating 
in the EU. The development of national regulation and supervision systems has moved towards the integration of the competent agencies.

Today, in most EU countries, the single regulator model is applied, which means supervising the entire financial system under the jurisdiction of an institution that includes prudential control and investor protection functions. In order to build the overall "architecture of financial stability", it is necessary to constantly improve cooperation between supervisory institutions, in order to grow; develop and ensure security and trust in national and supranational financial systems.

\section{REFERENCES}

- BIS., 2012. "Principles for the supervision of financial conglomerates", http://www.bis.org/publ/joint29.pdf

- Cukierman A., 2011. "Reflections on the crisis and on its lessons for regulatory reform and for central bank policies", Journal of Financial Stability 7(1), pp. 26-37.

- Erdélyi, 0 J., 2015. "Twin Peaks for Europe: State-of the-Art Financial Supervisory Consolidation", Springer.

- Goodhart, C. A. E., 2000. "The Organizational Structure of Banking Supervision ", FSI Occasional Papers, Financial Stability Institute, BIS, 1.

- Godwin, A., 2017. "Introduction to special issue - the twin peaks model of financial regulation and reform in South Africa ", Law and Financial Markets Review, 11:4, pp.151153, DOI: $10.1080 / 17521440.2017 .1447777$

- Nakeva Ruzin, A., and Jovanovski K., 2020. "Evolution of the Financial Supervision Architecture in the EU Member States-Potential Lessons for Reforming the Macedonian Financial Framework," Economic Development No. 1-2 pp.76-91

○ NIER, E. W., 2009. "Financial Stability Frameworks and the Role of Central Banks: Lessons from the Crisis ", IMF Working Paper, WP/09/70.

○ Olgić D, B.,2012. "Uloga i utjecaj institucionalnih investitora na razvoj tržišta kapitala odabranih tranzicijskih zemalja i RepublikeHrvatske", doktorska disertacija, Rijeka.

- Schich S, Kim B-H., 2011. "Guarantee arrangements for financial promises: how widely should the safety net be cast? “, OECD Journal: Financial Market Trends(1),pp.201-235.

- Schoenmaker, D, and Véron N., 2017. "A 'twin peaks' vision for Europe”, Bruegel Policy Contribution, no 30 .

- Van der Zwet, A., 2003. "The Blurring of Distinctions between Financial Sectors: Fact or Fiction? “, De Nederlandsche Bank, Occasional Studies, 1, 2.

○ http://www.ecb.europa.eu/press/key/date/2014/html/sp140212.en.html. 